\title{
Arte chancay: reconstrucción ritual del mundo
}

\section{CHANCAY ART: RITUAL RECONSTRUCTION OF THE WORLD}

Vicente Cortéz

Centro Peruano de Arqueología Marítima y Subacuática (CPAMS)

\section{RESUMEN}

Pocas culturas prehispánicas presentan manifestaciones formales tan claras y definidas como la cultura chancay. La originalidad de su arte revela una cultura autónoma y coherente que, a pesar de ser ampliamente reconocida, mantiene aún el velo de su pasado distante y esquivo. Hoy nos identificamos con sus formas estéticas, pero estamos todavía lejos de comprender plenamente el sentido de sus representaciones. En el presente artículo, se esboza una interpretación de algunas expresiones de la realidad cultural de Chancay a través de su producción artística, vinculada principalmente con los ritos funerarios y el culto a los antepasados. Se ordenará el corpus de representaciones en función de los tres temas básicos presentes en el ritual funerario, a saber: el carácter divino del ancestro, la recreación ritual del entorno y la asignación de sentido a la muerte de un miembro de la sociedad. Dentro de este contexto, trataremos de entender las particularidades de los cánones artísticos y las convenciones estilísticas que definen su arte. De esta manera, la iconografía y la estética nos permitirán reconstruir las concepciones culturales que definen cada objeto y, a partir de ello, aproximarnos a la cosmovisión que dio forma y sentido a la vida de la sociedad chancay.

PALABRAS CLAVE: cultura y sociedad chancay, cosmovisión, ritual funerario, arte, escenas

\section{ABSTRACT}

Few Pre-Hispanic cultures in the Andes have formal manifestations as clearly defined as the ones from the Chancay culture. The originality of its art reveals an autonomous and coherent culture, with a characteristic aesthetics that despite being widely known, still maintains the veil of mystery over its distant and elusive past. Today we can identify ourselves with their aesthetic expressions, but we are still far from fully understanding the meaning of their representations. This article outlines an interpretation of a section of the Chancay worldwiew through its artistic production, mainly connected to funeral rites and ancestors worship. We will look at the body of representations focusing on the main three themes connected to the funeral ritual: the divine character of the ancestor, the ritual recreation of the environment, and the assignment of meaning to the death of a member of society. Within this context, we will try to understand the particularities of the artistic canons and stylistic conventions that define the Chancay art. Iconography and aesthetics will allow us to attempt to rebuild the meaning of each object, and the worldview that shaped and gave meaning to the Chancay society.

KEYWORDS: Chancay culture and society, cosmovision, funeral rite, art, scenes 


\section{INTRODUCCIÓN}

Pocas culturas prehispánicas presentan manifestaciones formales tan claras y definidas como la cultura chancay. La originalidad de su arte revela una cultura autónoma y coherente que, a pesar de ser ampliamente reconocida, mantiene aún el velo de su pasado distante y esquivo. Hoy nos identificamos con sus formas estéticas, pero estamos todavía lejos de comprender plenamente el sentido de sus representaciones.

Tanto el nombre como el estilo cerámico chancay, en particular, son ampliamente reconocidos por su conspicua presencia en colecciones de arte precolombino, y por su uso actual como objeto decorativo. Sin embargo, a pesar de su abundancia, resulta sorprendente lo limitado de nuestros conocimientos sobre el tema y lo reducido de las investigaciones arqueológicas al respecto (Cortéz, 1998, p. 14). El escaso interés que despierta entre los arqueólogos el estudio de Chancay se debe al hecho de que gran parte del material existente en colecciones públicas y privadas no deriva de excavaciones científicas. Por lo mismo, las piezas de estas colecciones carecen de información contextual.

Paradójicamente, la arqueología científica en el Perú se inició precisamente en las cercanías del valle de Chancay a fines del siglo xIx. La construcción del ferrocarril de Lima a Ancón y el crecimiento de este balneario dejaron al descubierto un vasto cementerio prehispánico, lo cual promovió el interés por el coleccionismo y la adquisición de antigüedades. Hacia 1875, los geólogos alemanes Wilhelm Reiss y Alphons Stübel, reconociendo el valor excepcional de los restos, empezaron sus excavaciones pioneras en este sitio. La seriedad del registro sistemático que llevaron a cabo significó un verdadero hito en los estudios del Perú prehispánico. Su trabajo es hasta hoy material de consulta obligatoria para la arqueología de la costa central (Kaulicke, 1997).

Max Uhle, uno de los principales discípulos de Alphons Stübel y uno de los pioneros de la arqueología peruana, siguió los pasos de su maestro al realizar investigaciones en Ancón y en el valle de Chancay entre 1903 y 1904. De esta manera, Chancay tiene un lugar privilegiado en los inicios de la arqueología científica en el Perú. Sin embargo, lamentablemente, pocos proyectos arqueológicos se han realizado después en la región, con excepción de las investigaciones de Hans Horkheimer durante la década de 1960 (Horkheimer, 1962) y otros proyectos centrados en catastros arqueológicos o rescates frente al avance de la frontera agrícola y el desarrollo urbano. La mayor parte de estos trabajos están aún por publicarse o se han publicado solo parcialmente (Cortéz, 1998, p. 15).

En este artículo buscamos entender y explicar la función del arte en la sociedad chancay, intentando reconstruir el contexto y el uso ritual en el cual adquiría valor y sentido para esta sociedad prehispánica. Para ello, nos valdremos de los pocos estudios 
publicados sobre la cultura chancay y sobre otras sociedades contemporáneas a esta, así como de información etnohistórica y entrevistas realizadas por el autor durante sus años como director del Museo Municipal de Chancay. Paralelamente, trataremos de comprender las particularidades de los cánones artísticos y las convenciones estilísticas que definen el arte chancay. De esta manera, la arqueología, la iconografía y la estética nos permitirán reconstruir las concepciones culturales que definen cada objeto y, a partir de ello, nos aproximaremos a la cosmovisión que dio forma y sentido a la vida de la sociedad chancay.

\section{LA CULTURA CHANCAY}

Con este nombre se identifica a la cultura que tuvo su centro en el valle costero de Chancay y se extendió desde el vecino valle de Huaura en el norte hasta la zona de influencia de la cultura ychma (valle del Chillón, Rímac y Lurín) por el sur, durante el período Intermedio Tardío o de los Estados Regionales (1000 a 1475 d. C.).

El valle de Chancay se sitúa a unos 80 kilómetros al norte de Lima. Con una franja costera de unos 25 kilómetros de largo, el valle se va estrechando progresivamente camino a la sierra. De clima templado y algo caluroso, con escasa precipitación pluvial, el acceso al agua en el valle bajo depende de lo que aporta el río y de los afloramientos de la napa freática, poco profunda, sobre todo en las áreas cercanas al litoral. Estas zonas de albuferas y pantanos, como los de Boza, Santa Rosa y Chancayllo, eran ricas en totorales y estaban habitadas por gran cantidad de aves y peces. Del mismo modo, al norte del valle se alza una región de lomas costeras, como las de Lachay e Iguanil, cubierta en tiempos prehispánicos de bosques y pastizales. Hay que sumar a los recursos de la tierra aquellos que ofrecía el mar: mariscos, crustáceos y peces. Las salinas marinas que existen tanto al norte como al sur del valle permitían a los pobladores obtener sal para la conservación de sus alimentos, la sazón de sus comidas y el intercambio con las poblaciones de la sierra vecina. Por último, las islas guaneras constituían una importante fuente de abono para la agricultura (Cortéz, 1992).

Gracias a la explotación sostenida de los recursos que ofrecían estos variados ecosistemas del valle, la población de Chancay logró asegurar su subsistencia y generar excedentes que hicieron posible el surgimiento del estilo y la cultura en que "por primera vez el valle expresa su propia personalidad" (Horkheimer, 1970, p. 373).

La existencia, en el mismo período, del reino chimú en la costa norte - cuyos dominios se extendían hasta la zona de Pativilca, a unos 150 kilómetros al norte de Chancay-y del área de influencia del santuario y oráculo de Pachacamac, ubicado en el valle de Lurín a unos 100 kilómetros al sur, limitaron la expansión de la cultura chancay a su valle de origen y a algunos sitios en los valles de Huaura y Chillón. Esta situación geográfica y 
política determinó que la sociedad chancay se centrara en el aprovechamiento máximo de los recursos de su valle y, como consecuencia, generara en abundancia una cultura material propia y particular (Cortéz, 1998, p. 19).

La población se concentraba en asentamientos complejos, la mayoría distribuidos en o alrededor de la planicie agrícola. Destacan entre ellos los sitios monumentales de Lauri, Peralvillo y Puerto Chancay, Lumbra, Cuyo y Pisquillo Chico. Estos sitios cuentan con sectores bien delimitados, a manera de barrios, que albergan pirámides con rampa asociadas a plazas cercadas, complejos de palacios residenciales, zonas de viviendas, talleres y depósitos, posibles corrales y extensos cementerios (Krzanowski, 1991). Otros asentamientos menores distribuidos en el valle compartían características similares, sin la totalidad de los sectores. Tal es el caso de sitios como Tronconal, Huando, Huaral Viejo, Caqui, Pancha La Huaca, Macatón o Chancayllo, entre otros, así como el sitio de Tambo Inca en el valle de Chillón. Otros sitios complejos, por su ubicación, podrían asociarse a comunidades especializadas de pescadores, distribuidas a lo largo de la costa en lugares como Punta Grita Lobos en Chancayllo, los de La Mina y La Ollada en Puerto Chancay y en Pasamayo, al sur del valle; a estos últimos habría que sumar el sitio de Miramar en Ancón.

Las actividades agrícolas, de pesca, caza y pastoreo se vieron complementadas con el intercambio de bienes con pueblos de la sierra cercana. Este intercambio involucraba el comercio de productos para la subsistencia y el abrigo (pescado, sal, hilo de algodón y diversos frutos), así como bienes de lujo necesarios para los rituales de reciprocidad entre gobernantes y para los ritos propiciatorios o de pago a las divinidades tutelares. Se explica así que una parte importante de la actividad económica de la región estuviera dedicada a la producción manufacturera y artística, principalmente de cerámica y textiles, que se llevaba a cabo en los grandes asentamientos (Cortéz, 1998, p. 19).

\section{CARACTERÍSTICAS DEL ARTE CHANCAY}

Como mencionamos en la introducción, el principal problema en el estudio de cualquier aspecto de la cultura chancay es que la mayor parte del material que la identifica y que se conserva proviene de cementerios saqueados y carece de información de procedencia o de contexto (Watson, 2016). Esto dificulta mucho el entendimiento del desarrollo de su producción artística y artesanal, sus opciones estéticas y sobre todo la función social que cumplieron tales objetos. Sin embargo, el hecho de saber que la gran mayoría del material conocido venga de cementerios es un claro indicador de la estrecha vinculación entre el arte y las prácticas religiosas, una constante en las sociedades del antiguo Perú. Un análisis más detallado ayudará a inferir el sistema de creencias, las prácticas religiosas y la visión del mundo al que estaban asociadas estas manifestaciones artísticas. 
El material más abundante en las colecciones sobre Chancay es la cerámica: vasijas globulares de gran tamaño, de superficie alisada con su característica decoración de diseños geométricos. La importancia del estudio de la cerámica chancay radica en gran medida en que esta cultura ha sido definida con base en los restos materiales de la cerámica, textiles y metales encontrados dentro de tumbas (Watson, 2016).

La cerámica chancay, fabricada en grandes cantidades gracias al uso de moldes, se caracteriza por sus formas y diseños sencillos, mayormente contenedores: cántaros ovoides de cuellos ampulosos, platos, vasos, copas, cuencos y vasijas escultóricas que representaban figuras humanas, plantas y animales, al igual que figurinas antropomorfas y zoomorfas. El estilo denominado de Chancay Clásico o negro sobre blanco consiste en un baño de engobe blanco cremoso sobre el cual aparecen, pintados en negro, diseños geométricos sencillos. El aparente descuido en el producto final no es, como muchos asumen, un signo de limitación técnica; se trata más bien de una manifestación de la sencillez y sobriedad que caracterizan a la estética chancay.

\section{Antecedentes y fases de la cerámica chancay}

\section{Huaura (700-1000 d. C.)}

La cultura huaura es, sin duda, el principal antecedente iconográfico y formal del arte chancay. Huaura se desarrolló en los valles de Huaura y Chancay durante el Horizonte Medio (700-1100 d. C.), en el cual existió una fuerte interrelación regional. Es un período de transición y recomposición, luego del colapso de las sociedades del período Intermedio Temprano (200-700 d. C.). Durante el Horizonte Medio, las culturas costeñas incorporaron a su repertorio motivos propios de la región sur andina. A través del arte wari, por ejemplo, Huaura fue asimilando decoraciones figurativas, como la serpiente de dos cabezas en forma de arcoíris, el personaje central con báculos y tocado de penachos, grifos y felinos. Estos nuevos motivos fueron integrados a elementos estilísticos derivados de culturas anteriores de la costa como Lima. Así, en las telas pintadas asociadas al estilo huaura pueden coexistir los seres marinos de la iconografía de Lima con el personaje de cabeza radiante típico del estilo wari.

La cerámica huaura se caracteriza por la presencia de cántaros globulares, de base ancha, con asas y cuello recto revertido o ampulosos. Estas formas, que no habían aparecido antes en la costa central, significaron un aporte novedoso para los alfareros de la zona. En su decoración polícroma predominan el rojo, negro, blanco y gris, colores que usualmente eran aplicados sobre una base de color rojo ladrillo. El acabado de las vasijas es pulido. 
Chancay Temprano (1000-1250 d. C.)

El desarrollo de Chancay es quizá uno de los mejores ejemplos de cómo, durante el período Intermedio Tardío (1100-1475 d. C.), se van consolidando culturas definidas con manifestaciones estéticas particulares y propias. Sobre la infraestructura dejada por las anteriores sociedades de Lima y Huaura, en el valle de Chancay emerge entonces una nueva cultura (Cortéz, 1998, p. 23).

A partir de los aportes culturales y estilísticos de Huaura, se empieza a definir la estética propia de la cultura chancay. La cerámica, de formas globulares, se distingue por su decoración, que llegará a ser el elemento típico de Chancay: sobre un baño de engobe blanco cremoso se pintan diseños geométricos, generalmente inspirados en el arte textil. El acabado de las piezas es alisado. En un primer momento, seguirán apareciendo diseños figurativos que repiten motivos del Horizonte Medio, como la divinidad central debajo de la serpiente de dos cabezas. En esta fase formativa de Chancay, domina el estilo tricolor geométrico, con diseños estilizados de colores rojo y negro aplicados sobre un fondoblanco.

\section{Chancay Clásico (1200-1475 d. C.)}

Esta fase marca el auge de la cultura chancay. La consolidación económica y social se ve reflejada en el arte, que en ese momento desarrolla su estilo cerámico característico: el Chancay negro sobre blanco. La abundante producción de esa época, basada en el uso de moldes, sugiere la imagen de una sociedad en pleno crecimiento, que puede aplicar sus recursos a la pompa y boato de su ceremonial funerario (Cortéz, 1998, p. 24).

Presente desde la fase anterior, la decoración negro sobre blanco se aplica sobre cántaros de forma ovoide con golletes ampulosos. Las vasijas van adoptando formas ovoides y se hacen más frecuentes las representaciones moldeadas y aplicadas de figuras humanas, animales y plantas. Al mismo tiempo, la decoración se simplifica al máximo, reduciéndose a diseños geométricos en negro sobre el fondo blanco cremoso que recubre la vasija. El acabado de las piezas es alisado. Existen algunas excepciones como las vasijas negras, de cocción reducida y el acabado pulido, testimonio del contacto con otras tradiciones manufactureras como el estilo chimú.

Un tipo de ceramio característico de esta fase y con una función netamente funeraria corresponde a los cántaros antropomorfos. Destacan de manera particular las representaciones de celebrantes, conocidas comúnmente como "chinas" (por la pintura facial, en especial alrededor de los ojos). Se trata de personajes de alto estatus, probablemente señores o cabezas de familia, pues tienen pintura facial, orejeras, pectorales y tocados cilíndricos a manera de corona. Se les representa sosteniendo vasos o copas. Otros cántaros antropomorfos muestran a cargadores de objetos diversos (cántaros, 
bultos) y animales, con el cuerpo pintado de negro, sin orejeras, aunque a veces pueden usar pendientes. En vez de tocados, llevan una cinta alrededor de la cabeza con un disco a la altura de la frente. Una variante de estos personajes son las mujeres cargadoras, con el cuerpo pintado de negro, con tupus a la altura del pecho y con los senos evidentes. Estas suelen cargar niños en sus brazos, así como bolsas o chuspas que sostienen con la frente.

Si bien las figurinas antropomorfas aparecen en todas las fases, durante el Chancay Clásico surge el cuchimilco, que representa mayormente a mujeres (aunque también se han encontrado figurinas masculinas con menor frecuencia) que tienen los brazos extendidos.

En esta fase, los arqueólogos han intentado diferenciar subestilos en función de un supuesto desarrollo cronológico (Cornejo, 1985, 1992). Sin embargo, las excavaciones realizadas por el autor (Murro, Cortéz y Hudtwalcker, 1997) y los recorridos por los distintos sitios y cementerios del valle de Chancay indicarían que las diferencias estilísticas identificadas en Chancay Clásico no corresponderían tanto a una secuencia cronológica, sino que más bien podrían tratarse de diferencias socioeconómicas y regionales. De hecho, se observan sutiles diferencias estilísticas entre los materiales procedentes de distintos sitios arqueológicos, como Chancayllo, Lauri y Pisquillo Chico (Cortéz, 1998, p. 24).

Es solo hacia el final de esta fase que Chancay incorpora formas y técnicas de otras culturas. Algunos ejemplares, por ejemplo, denotan claramente la presencia del estilo chimú.

\section{Chancay Tardío (1475-1533 d. C.)}

La desarticulación de la sociedad chancay y el despoblamiento de la región parecen haber precedido a la llegada de los incas a la zona durante el Horizonte Tardío. Al parecer, el dominio inca en la región se dio a través de los sitios de mando en Chancay, en los cuales se fueron estableciendo los nuevos gobernantes. El arte chancay muestra claramente la presencia del Tahuantinsuyo en el territorio. Tal es la aparición de cántaros con formas similares a los aríbalos (Cornejo, 1985), pero que siguen siendo decorados con la técnica de Chancay negro sobre blanco. El acabado es alisado, aunque resurge el uso del engobe rojo: el subestilo negro y blanco sobre rojo consiste en la aplicación de la decoración negro sobre blanco en la parte superior de la vasija, mientras que la parte inferior está pintada de engobe rojo, muchas veces pulida.

Aunque la producción se ve reducida, destacan piezas de singular belleza donde conviven formas y personajes chancay con diseños incas. En una de ellas, el típico perro sin pelo de Chancay se monta sobre un animal de origen estilístico netamente cusqueño. 
Los incas trasladaron también pueblos muchik al sitio de Pasamayo (Rostworowski, 1978). A ese lugar, los mitimaes de origen norteño parecen haber importado sus propias formas artísticas. De hecho, son frecuentes las piezas en que se nota la confluencia del estilo chimú-inca y el de Chancay.

\section{Particularidades de la cerámica chancay}

La cerámica chancay, comparada con la desarrollada por otras culturas prehispánicas, se caracteriza por su austeridad y la sencillez hasta cierto punto naíf de sus representaciones, tanto formal como en sus acabados, razón por la cual es tan popular entre el público contemporáneo. Esta sobriedad contrasta con la abundancia en la que aparece en los contextos funerarios, superando el centenar de piezas por tumba (Murro et al., 1997). Aparentemente, no existió un repertorio definido de vasijas funerarias, pues destacan los cántaros, ollas, platos, vasos y cuencos, cuya fragmentería no solo se reconoce en los cementerios saqueados, sino que aparece también en la superficie y en los rellenos constructivos de los sitios habitacionales o monumentales. Una mención aparte merecen los cántaros antropomorfos, las vasijas zoomorfas escultóricas, las figurinas y las vasijas silbadoras de doble cuerpo, asociadas casi exclusivamente a los sitios funerarios. Estas últimas formas también comparten el acabado de tipo alisado y la decoración del estilo negro sobre blanco con las demás vasijas de tipo contenedores.

Por mucho tiempo, la sencillez estilística se identificó con la pobreza de medios. Sin embargo, los chancay, herederos de la policromía de la cerámica de Lima y Huaura, conocían e incluso aplicaron -en un grado menor- las técnicas de decoración más elaboradas, tales como el uso de otros colores además del blanco y negro, la técnica de cocción reducida (cerámica negra) y el pulido en el acabado de algunas piezas. Esto se debe al intercambio de bienes, tanto como tradiciones y tecnologías, con las sociedades contemporáneas y vecinas. Evidencia de ello es la presencia de vasijas de los estilos de Huaura, Supe o Pativilca, Chimú, Ychma, Lauri impreso y de la sierra cercana (Atavillos), cuya cerámica también aparece en los contextos funerarios asociados al material y a la tradición chancay. El hecho de que no existiera un repertorio exclusivo de vasijas funerarias - con excepción de las figurinas, los cántaros antropomorfos y las botellas silbadoras- hace suponer a algunos investigadores que no se estaría restringiendo o controlando las formas de producción alfarera durante este período. Esto sugiere una mayor independencia en la producción de cerámica y mayor comercialización de productos con diferentes talleres (Watson, 2016).

Teniendo en cuenta la aparente prosperidad que esta sociedad alcanzó -reflejada en la gran cantidad de ecosistemas que sus pobladores supieron aprovechar, en la concentración de asentamientos complejos distribuidos en su área de influencia y en la escala de sus ajuares funerarios-, la sencillez formal de su cerámica, el sintetismo en 
las representaciones y la sobriedad de sus líneas nos hace pensar que estas características, más que causadas por limitaciones económicas, tecnológicas o de recursos, serían más bien una opción estética, que produjo un mundo formal autónomo y coherente (Cortéz, 1998, p. 50). La austeridad de la cerámica misma contrasta con la riqueza del diseño pictórico aplicado: Chancay ejercitó en la pintura una libertad que no tiene paralelo en otras culturas prehispánicas, logrando en este campo una gran espontaneidad al incorporar lo aleatorio como parte del proceso creativo. Este "descuido intencional" se refleja en el acabado de algunas piezas, que muestran los trazos del engobe fresco que discurre más allá de la línea trazada, correspondiente al motivo o diseño que se representa. Este aparente descuido es muy fácil de corregir con el engobe fresco, solo se necesita pasar un paño húmedo. Sin embargo, el artista anónimo chancayano optó por dejar la pieza de este modo. Lo mismo sucede con algunos cántaros que se deformaron o quemaron durante el proceso de cocción, los cuales hubieran podido ser descartados por el ceramista, pero que, sin embargo, aparecen en los entierros. Creemos, como lo veremos más adelante, que para los pobladores de Chancay más importante que el aspecto final de la pieza era el rol específico que cumpliría en los rituales de los que iba a formar parte.

Otra característica particular de la cerámica chancay es la escala y dimensión de sus piezas. Sus ceramios son de un tamaño mayor al usual en otras culturas. Esto ha hecho que se vuelvan populares entre los coleccionistas, sobre todo como objetos decorativos para el interior de las viviendas limeñas o en lugares públicos como hoteles, oficinas o restaurantes exclusivos, donde se exhiben en salones o en espacios abiertos como terrazas y patios. El tamaño se debe a que muchos de los cántaros recuperados de las tumbas, por ejemplo, parecen haber servido precisamente para contener líquidos, al igual que las ollas con alimentos, ya que al momento de ser exhumados se encontraban cuidadosamente tapados por platos, vasos o cuencos y en su interior se halló alimentos (como ocurre en las ollas o ánforas) o restos de almidón, probables residuos de la chicha encerrada en las botellas o cántaros. Lo mismo sucede con los cántaros antropomorfos, tales como los celebrantes o cargadores de ofrendas que, aparte de servir de contenedores de líquidos, aparecen distribuidos en grupos, junto a los cántaros y agrupamientos de platos y ollas con alimentos, como si estuvieran participando de un banquete, como lo veremos más adelante. En estos casos, la escala misma otorga al objeto un peso simbólico y formal, que imprime a las figuras escultóricas y a los cántaros antropomorfos un poder expresivo singular (Cortéz, 1998, p. 50).

\section{La textilería chancay}

El mayor logro artesanal de Chancay es, sin lugar a dudas, la textilería. Las hilanderas y tejedoras chancayanas perfeccionaron una enorme diversidad de técnicas de fabricación y decoración textil, desde el tejido llano decorado por tintes con las técnicas del batik y 
del tie-dye, hasta las más finas gasas, encajes, brocados, calados y reticulados, así como los tejidos de doble cara y los tapices kílim de gran policromía. Predominan en este arte textil los colores rojo, amarillo, marrón, crema y azul, los motivos geométricos y las repeticiones de personajes antropomorfos y zoomorfos (Cortéz, 1998, p. 21).

A diferencia de la cerámica, la misma naturaleza de las técnicas de producción textil -en donde la manufactura y la decoración van de la mano- no permiten error alguno, por lo que el resultado son piezas decoradas de gran simetría y belleza, con motivos ordenados y repetitivos. La única excepción son las telas pintadas, cuyos trazos y motivos pintados a mano comparten el espíritu libre y espontáneo del trazo que se aprecia en la decoración de la cerámica.

Los textiles que se conservan fueron recuperados del interior de los fardos funerarios. Esto los vincula directamente a los individuos enterrados y al ritual que buscaba convertirlos en ancestros. Igualmente, en los entierros chancay es significativa la presencia de instrumentos textiles como espadas de tejer, agujas e hilos, dispuestos en paquetes o dentro de canastas y costureros de caña, carrizo o mimbre. Muchas de las herramientas textiles se asocian a entierros de mujeres (Watson, 2016); sin embargo, algunas otras herramientas se encuentran en el interior del fardo ayudando a darle forma a este. En todo caso, la presencia de tejidos a manera de ofrendas y de herramientas textiles, también como elementos estructurales de los fardos, nos habla de la importancia de la textilería en el ritual funerario.

Otra evidencia de la importancia de la textilería para los antiguos chancayanos es que los motivos geométricos y figurativos estilizados presentes en la decoración de la cerámica son de indudable influencia textil. Más que representaciones de escenas o símbolos en la decoración de los estilos negro sobre blanco o incluso en el tricolor geométrico, diera la impresión de que el ceramista de Chancay quiso "vestir" los cántaros cubriéndolos con los diseños pintados a manera de mantos. En este caso, la fluidez e irregularidad de las líneas dan a los ceramios esa sensación de levedad, ligereza y a la vez volumen que tiene un tejido que recubre un objeto.

Otros objetos textiles de los que se puede extraer mucha información son las "muñecas" de Chancay. Se trata de figuras tanto de hombres como de mujeres, hechas de hilo con alma de totora; llevan ropa tejida en técnica de tapiz al igual que los rostros, y sus diseños emulan pintura facial o tatuajes. Justamente es por la vestimenta y los tatuajes que se puede reconocer a qué genero pertenecen los personajes. Las muñecas aparecen en el nivel más profundo de la tumba, junto al fardo. En algunos casos, solo hay una muñeca; en otros, se han encontrado grupos de ellas, cosidas a cojines a manera de plataformas donde se representan escenas de diversas actividades. Estas representaciones muestran los ritos vinculados al proceso de entierro y al culto a los ancestros. 


\section{CONTEXTUALIZACIÓN DEL ARTE CHANCAY}

Para llegar a saber la función y el sentido de cada objeto - y, finalmente, el espíritu creativo que le dio origen-, hay que entender e identificar el uso original que tuvo; para ello es vital examinar el contexto en el cual se encontró. Entendiendo su relación con los demás elementos del contexto, con el entorno del lugar en donde se halló, nos acercaremos a la gente que lo usó y el sentido y el valor que tuvo para ellos.

Las piezas chancay que se conservan en colecciones públicas y privadas proceden, casi en su totalidad, de los extensos cementerios distribuidos en el valle. El hecho de que la producción artesanal estuviera asociada principalmente a los contextos ceremoniales de carácter funerario indica la estrecha vinculación entre el arte y las prácticas religiosas, y nos permite inferir el sistema de creencias y la visión del mundo al que estaban asociadas estas manifestaciones artísticas (Cortéz, 1998, p. 26).

\section{Escenas y temas}

En el arte chancay es frecuente encontrar representaciones individuales de la figura humana, tanto de hombres como de mujeres, con atributos variados y en actitudes diversas. En la cerámica destacan los cántaros antropomorfos de gran tamaño ("chinas" o "chinos"), entre otros, así como las figurinas (entre las que sobresalen los famosos cuchimilcos). Estos personajes se asocian con el ritual funerario, pues fueron hallados al interior de las tumbas; pero resulta difícil establecer sus contextos originales o sus funciones particulares y la relación entre ellos. De hecho, uno de los principales problemas de interpretación que presenta la iconografía chancay es la ausencia de composiciones complejas, de escenas en las que aparezcan estos personajes interrelacionándose entre sí, o de representaciones que aludan a temas míticos (Cortéz, 1998, p. 38).

La excepción a esta regla son los cojines o almohadas de tela sobre las que aparecen las muñecas que representan personajes en actividades diversas. Un cojín conservado en el Museo Amano muestra una escena que tiene lugar dentro de una casa: al fondo de una habitación encontramos a un hombre y a una mujer rodeados de personajes de ambos sexos con copas en la mano y acompañados por un músico tocando una flauta. Otro cojín, en el mismo museo, representa una danza, en la cual participan hombres y mujeres que se dan la mano para formar una ronda alrededor de un árbol. Junto a este árbol, ricamente decorado con frutos de diversos colores, se ubica un músico que toca un tambor. Aún hoy en los Andes se realiza la tradicional celebración del tumbamontes o yunza, en la cual se danza alrededor de un árbol adornado con diversos productos y guirnaldas de colores. Aunque resulta peligroso realizar paralelos entre las escenas precolombinas y las festividades actuales, es claro que, en ambos casos, existe una estrecha relación entre la danza comunitaria y la producción agrícola y la fertilidad. 
Una obra similar en la misma colección muestra danzas en las que participan solo los hombres. En otra composición aparecen mujeres a manera de danzantes acompañadas de un músico. Todos los personajes llevan motas de algodón alrededor del cuello. Esta última representación los relaciona con la producción textil. A esta se asocian en particular algunos cojines conservados, en los cuales aparecen mujeres en plena labor textil. En estas escenas las mujeres se encuentran hilando, tejiendo o mostrando paños, lo cual indica la importancia de la textilería como actividad femenina en la sociedad chancay.

Un cojín en el Museo Larco, tradicionalmente descrito como la escena de una "curación", presenta a varios personajes masculinos con tocado bilobado que rodean un cuerpo echado sobre una manta. Dado el contexto en el que se recuperó la pieza, sugerimos más bien que la escena ilustraría una parte del proceso del ritual funerario, relacionada con el tratamiento del cuerpo y el inicio del enfardelamiento del difunto.

\section{La escenografía ritual}

Como lo hemos mencionado líneas arriba, en el caso de los personajes representados de forma individual en los ceramios procedentes de los cementerios chancay, estos parecen aludir a miembros de la sociedad que participan en el ritual funerario. Al no contar con escenas complejas en donde se les vea participar, las relaciones entre aquellos podrían inferirse al compararlas con personajes análogos que aparecen en algunas escenas de la iconografía de culturas contemporáneas con las cuales los chancay mantuvieron estrechos lazos. Tal sería el caso de la cultura chimú.

Como parte del Proyecto Arqueológico Huacas de Moche, los arqueólogos de la Universidad Nacional de Trujillo excavaron un entierro chimú tardío en el Templo de la Luna y descubrieron una serie de maquetas y escenas con figurinas de madera relacionadas con el culto funerario (Uceda, 1997). Una de estas escenas corresponde al modelo de una pirámide con rampa y plaza cercada, como las que existen en las ciudadelas chimú de Chan Chan o incluso en asentamientos chancay como Pisquillo Chico o Lauri. Sobre la explanada, un grupo de señores, con tocado y orejeras, aparecen sentados alrededor de un gran cántaro. Unos jorobados extraen el líquido de este recipiente para servirlo a estos señores celebrantes. Junto a este grupo aparecen también otros personajes, músicos con tocado bilobado, que tocan flautas y tambores. Personajes pintados de negro alternan entre los grupos de músicos y los bebedores portando objetos y animales.

En un recinto adyacente a la plaza, sobre una plataforma central se encuentran tres fardos funerarios, en honor de los cuales se realizaría el ritual en la plaza. En el mismo contexto se hallaron también unas tarimas con figurinas de madera, dos de las cuales representan una procesión funeraria: unos hombres cargan en una suerte de anda lo que parece ser un cadáver, acompañados por portadores de ofrendas, músicos y mujeres con niños. En otra tarima aparece una recua de llamas, presidida por un músico. 
Estas escenas de la iconografía chimú son muy ilustrativas de algunas actividades en las que distintos personajes de la sociedad participan en las etapas del proceso de entierro, y del uso que se dio a algunos espacios arquitectónicos como las pirámides con rampa y sus plazas cercadas. Como veremos más adelante, muchos de estos personajes tienen sus paralelos en la iconografía chancay, lo cual nos ayudará a asignar un rol a algunas de las representaciones antropomorfas en su cerámica y, a la vez, hará posible entender la relación de los ceramios y personajes en los contextos funerarios.

Todos los personajes que aparecen en las figurinas y vasijas escultóricas chancay se han hallado dentro del pozo de la tumba, junto con otras piezas, formando composiciones que constituyen verdaderas "escenografías rituales" (Kaulicke, 1997, p. 39). Sosteniendo sus copas, los señores celebrantes representados por los cántaros antropomorfos tipo "chinas" se encuentran en grupo, asociados a una serie de cántaros de formas sencillas que contendrían el líquido (posiblemente la chicha) que beben y ofrendan. Los cargadores de objetos y animales, junto a las mujeres que cargan niños, se integran a estos grupos, como presentándoles sus ofrendas. Muy cerca de estos personajes se depositan generalmente platos con ollas y alimentos. Estas agrupaciones de cántaros antropomorfos junto a los contenedores de chicha, ollas y platos con alimentos pueden repetirse en niveles superpuestos, alrededor y por encima del fardo. Estos grupos depositados por niveles podrían representar a los diversos grupos familiares vinculados a los individuos enterrados, que participan en la ceremonia de entierro a través de rituales y festividades que implican la presentación y depósito de ofrendas, así como la ingesta de alimentos y bebidas.

La ubicación de otros personajes frecuentes en la cerámica chancay, tales como los jorobados - representados en vasos antropomorfos- o los músicos de tocados bilobados - muy comunes en las botellas silbadoras-es más incierta. Algunos testimonios de huaqueros sitúan a los jorobados cerca del fardo. En los pocos contextos registrados que presentan personajes de músicos, estos aparecen al pie o cerca del fardo. Ello indicaría, como lo muestra también la maqueta chimú, el estatus especial de los jorobados -frecuentemente representados portando tocados, orejeras y pectorales, al igual que los señores celebrantes-y su estrecha vinculación con el culto funerario, en especial, con el fardo ancestro. Del mismo modo, la presencia de los músicos cerca del fardo nos hace pensar en la importancia de la música en la religión, pues estos personajes aparecen asociados a rituales propiciatorios o de fertilización, tales como las danzas alrededor del árbol, escenas de unión o de producción textil. También en ritos de pasaje como las ceremonias funerarias, en donde participan diversos personajes de la sociedad para asegurar el viaje del difunto al más allá y su transformación en ancestro.

En los niveles inferiores del pozo, junto al fardo, se encuentran cajas con adornos de metal, cuentas y orejeras, costureros, muñecas (solas o formando escenas), figurinas 
zoomorfas, fitomorfas y antropomorfas, pequeñas vasijas escultóricas y, con mayor frecuencia, cuchimilcos, además de vasijas de gran calidad estética como cántaros muy elaborados de tamaño menor a lo normal para la tradición chancay, cuencos y copas finas, al igual que las botellas de doble cuerpo silbadoras con representaciones de animales o de músicos. Igualmente, suelen aparecer en este nivel restos de animales como camélidos jóvenes, loros y hasta monos (Cortéz, 1998, p. 49). La presencia de objetos suntuosos y de estos personajes antropomorfos (músicos, cuchimilcos), así como de ofrendas o representaciones de animales o frutos, podrían aludir a la fertilización, y a otro elemento importante del ritual funerario y del proceso de entierro, que es el rol del o de los individuos enterrados y su transformación en un nuevo ser: el ancestro fundador de linaje, responsable de restaurar el orden divino y terrenal.

\section{El rol del ancestro y el orden natural}

Los fardos funerarios más tempranos de Chancay estaban dotados de una cabeza falsa, que les daba el aspecto de muñecos. Esta tradición sugiere un intento de transformar al difunto en un nuevo ser que, gracias a los rasgos de la máscara, puede ser identificado con la divinidad tutelar representada en la cerámica y los tejidos. Los mejores ejemplos de esta representación, sin embargo, corresponden a las telas pintadas que, si bien se hallan desde la época de Huaura, pueden asociarse a las primeras fases del desarrollo de Chancay. En estas telas se muestra un ser de apariencia humana con apéndices radiantes que surgen de su cuerpo o de su cabeza. Completan el espacio de la representación figuras de peces y seres marinos, la "serpiente celestial" o arco rematado por dos cabezas de felino, estrellas con claras alusiones al mundo celeste y felinos, representantes míticos del mundo terrestre. En algunas tabletas funerarias (planchas de madera pintada y labrada) aparece la cara del mismo personaje mítico presente en las telas pintadas (Cortéz, 1998, p. 28).

Otras telas muestran personajes de rasgos similares a los de los rostros de las máscaras de madera o tela que hacían las veces de cabeza de los fardos funerarios. Todos estos objetos se hallan dentro del fardo, junto al individuo enterrado. Esta asociación permite suponer que el propósito de tales objetos era identificar al difunto con la divinidad, identificación por la cual se buscaba convertir al cadáver en un ancestro mítico y garantizarle así, aun después de muerto, una función tutelar con respecto a la sociedad (Cortéz, 1998, p. 28).

Relacionados directamente con el fardo, se colocaban también tejidos y piezas de cerámica en los que se representaban los productos del mundo marino y terrestre. Dentro del fardo mismo, se ponía una serie de tejidos, en los cuales se observa toda la gama de técnicas manejadas por los chancay. Las imágenes representadas en estos mantos aluden a los espacios naturales con los que interactuaba el hombre. El hecho 
de que estos temas se plasmaran sobre el soporte textil y en exacto orden sugiere un intento por preservar el ordenamiento del universo, tarea encomendada, con seguridad, al difunto-ancestro.

El mar fue objeto de veneración para los chancay, no solo por ser una fuente importante de recursos, sino también por ser considerado como la morada de los muertos y antepasados. Los pobladores de Chancay rendían culto a las islas y peñones (Rostworowski, 1997), pues pensaban que se trataba de una primera humanidad creada por el dios Pachacamac (Duviols, 1983, p. 388). Las comunidades de pescadores creían, además, que las islas servían de morada para las almas de los muertos, a las que llegaban conducidas por lobos de mar (Duviols, 1976, pp. 47-48). Estas mismas islas proveían a los pobladores del valle del guano necesario para la agricultura. Este insumo era recogido periódicamente por individuos seleccionados especialmente para la tarea y dirigidos por un sacerdote (Duviols, 1976, p. 49). Esto explica quizá la frecuencia con la que aparecen en la iconografía chancay, tanto en los textiles como en la cerámica, imágenes de aves guaneras y de la fauna marina, así como representaciones de pescadores y embarcaciones, que parecen aludir a los ciclos de viaje a las islas guaneras.

Otras representaciones recurrentes en el arte chancay son las de animales y plantas, tanto en el soporte textil como en la cerámica de forma escultórica o aplicada. Según documentos de la campaña de extirpación de idolatrías, a inicios de los años 1600 aún existía la creencia entre los agricultores del valle de Huaura de que las almas de los difuntos se trasladaban a un mítico valle denominado Coaica o Loaica, que gozaba de fértiles tierras donde la producción de toda clase de frutos era excepcional en calidad y cantidad (Duviols, 1976, p. 47). Las representaciones de frutos y plantas en la cerámica chancay, ya sea de forma escultórica o aplicada en las vasijas, se caracterizan por su realismo y rasgos excepcionales.

Los animales también aparecen asociados a las plantas, particularmente el loro y el mono. Aunque a veces es difícil determinar el significado de la relación que se establece entre ellos, se puede comprobar que el loro con frecuencia está asociado al maíz y el mono a frutos como el pepino dulce o la lúcuma. En la cerámica estampada de Pativilca - contemporánea al estilo huaura antecedente de Chancay-, la escena de cópula entre un personaje masculino de rasgos divinos y una mujer suele estar rodeada de representaciones de árboles en los cuales aparecen monos comiendo estos frutos. Es probable, entonces, que esta asociación en Chancay aluda quizá a un mito similar de fertilización y creación. Por otra parte, el felino aparece también con frecuencia en la iconografía chancay. Las representaciones escultóricas o aplicadas en la cerámica del perro sin pelo peruano son también numerosas. En los mismos testimonios sobre el viaje de los difuntos al valle de Loaica o Coaica se menciona que este animal era el encargado de guiar a las almas a la nueva tierra, función para la cual era criado y sacrificado (Duviols, 
1976, p. 47). Esta hipótesis se vería confirmada por el hecho de que se han registrado entierros chancay con restos de estos perros dentro de pequeños fardos ubicados muy cerca de la boca de la tumba, a manera de ofrendas al entierro principal (Cornejo, 1985).

\section{IDEAS FINALES}

El poblador de Chancay plasmó su universo, tanto real como mítico, en sus representaciones artísticas. Con su plástica y estética particular, estas nos hablan de un mundo formal autónomo y coherente, cuyo sentido fue totalmente interiorizado por cada miembro de la sociedad.

Dedicado al culto de los ancestros, el arte chancay tuvo como objeto crear las condiciones ideales para el viaje del difunto y la perpetuación de su sociedad. Aun así, la pompa y el boato del contexto funerario no radica en los objetos mismos, sino en el arte de disponerlos, en la opulencia y excelencia de este ritual que recrea el mundo mítico y natural de Chancay (Cortéz, 1998, p. 51).

El fardo funerario, como unidad corporal, estaría asociado con un ancestro común, y su ajuar haría alusión al universo ideal, ordenado y en equilibrio, al que el fardo -ahora ancestro- pertenece y cuya regeneración, a la vez, asegura. Las ofrendas depositadas dentro o junto al fardo tienen una relación directa con este, con su viaje al otro mundo y con el nuevo rol divino y fertilizador que se le asigna.

Las ofrendas y objetos depositados en el pozo de la tumba, alrededor y encima del fardo, corresponden a los diversos pasos del ritual en el que participa la sociedad -en especial, los deudos - con el objeto de transformar al individuo o los individuos enterrados en ancestros para garantizar un intermediario con el mundo divino. Las vasijas antropomorfas y su posición nos ilustran acerca de los participantes y etapas del ritual, en el que compartir alimentos y bebidas con el ancestro era un acto significativo, como lo demuestra la presencia de platos, ollas con comida y cántaros en el entierro. La cantidad de cerámica agrupada en estos conjuntos escenográficos, dispuestos en niveles superpuestos dentro del pozo funerario, estaría relacionada con los distintos grupos familiares vinculados al ancestro identificado con el fardo. El éxito de tal rito propiciatorio dependería de la correcta participación de la comunidad en un acto que involucraba a todos, que dependía del entretejido de las relaciones sociales y aseguraba su subsistencia y su relación armoniosa con el entorno (Cortéz, 1998, p. 49).

Aisladas, las obras que todos conocemos de Chancay solo pueden mantener nuestro interés en un aspecto meramente formal, ya que apreciamos el sintetismo de sus representaciones, la libertad de su trazo y la sobriedad de sus líneas. La sintonía de su diseño con la sensibilidad moderna ha asegurado su posición como uno de los estilos más valorados por el público contemporáneo. Y, sin embargo, la arqueología recién empieza a 
comprender que el arte chancay refleja la cosmovisión de una cultura altamente avanzada y compleja.

\section{REFERENCIAS}

Cornejo, M. (1985). Análisis del material cerámico excavado por Hans Horkheimer en 1961, Lauri, valle de Chancay (memoria para optar al grado de bachiller). Pontificia Universidad Católica del Perú.

Cornejo, M. (1991). Patrones funerarios y discusión cronológica en Lauri, valle de Chancay. En A. Krzanowski (Ed.), Estudios sobre la cultura Chancay (pp. 83-113). Cracovia: Universidad Jagellónica.

Cornejo, M. (1992). Cronología y costumbres sepulcrales en Lauri, valle de Chancay. En D. Bonavía (Ed.), Estudios de arqueología peruana (pp. 311-330). Lima: Fomciencias.

Cortéz, V. (1992). Chancay préhispanique: au pays des fileurs de coton. Les Dossiers d'Archéologie, Edition Spéciale, 2, 22-29.

Cortéz, V. (1998). Arte Chancay: visión ritual del mundo. En Contemporaneidad del arte Chancay. Catálogo de la V Bienal Arte y Empresa (pp. 10-57). Lima: COSAPI Organización Empresarial, Museo de Arte de Lima.

Duviols, P. (1976). La Capacocha. Mecanismo y función del sacrificio humano, su proyección geométrica, su papel en la política integracionista y en la economía redistributiva del Tawantinsuyo. Allpanchis, 8(9), 11-57.

Duviols, P. (1983). El Contra idolatriam de Luis de Teruel y una versión primeriza del mito de Pachacámac-Vichama. Revista Andina, 1(2), 385-392.

Horkheimer, H. (1962). Arqueología del valle Chancay [folleto de la exposición en el Museo de Arte de Lima]. Lima.

Horkheimer, H. (1970). Chancay prehispánico: diversidad y belleza. En R. Ravines (Ed.), 100 años de arqueología en el Perú (pp. 363-378). Lima: Instituto de Estudios Peruanos. (Trabajo original publicado en 1963).

Kaulicke, P. (1997). Contextos funerarios de Ancón. Esbozo de una síntesis analítica. Lima: Pontificia Universidad Católica del Perú, Fondo Editorial.

Krzanowski, A. (1991). Observaciones sobre la arquitectura y patrón de asentamiento de la cultura Chancay. En A. Krzanowski (Ed.), Estudios sobre la cultura Chancay (pp. 37-56). Cracovia: Universidad Jagellónica.

Murro, J. A., Cortéz, V., y Hudtwalcker, J. A. (1997). Resultados preliminares del Proyecto de Rescate Puerto Chancay 93. Boletín de Arqueología PUCP, 1, 253-264. 
Rostworowski, M. (1978). Señoríos indígenas de Lima y Canta. Lima: Instituto de Estudios Peruanos.

Rostworowski, M. (1997). The Coastal Islands of Peru: myths and natural resources. En K. Berrin (Ed.), The Spirit of Ancient Peru. Treasures from the Museo Arqueológico Rafael Larco Herrera (pp. 33-39). Nueva York: Thames and Hudson.

Uceda, S. (1997). El poder y la muerte en la sociedad Moche. En S. Uceda, E. Mujica y R. Morales (Eds.), Investigaciones en la Huaca de la Luna, 1995 (pp. 177-188). Trujillo: Facultad de Ciencias Sociales de la Universidad Nacional de La Libertad.

Watson, L. (2016). Vida y muerte en la costa central del Perú de los períodos tardíos (800 d. C. - 1532 d. C.): análisis de los fardos funerarios de Ancón desde la perspectiva bioarqueológica (tesis de doctorado). México: Universidad Nacional Autónoma de México. 